\title{
A Delphi study of medical professionalism in Arabian countries: The Four-Gates model
}

Citation for published version (APA):

Al-Eraky, M. M., Donkers, J., Wajid, G., \& van Merrienboer, J. J. G. (2014). A Delphi study of medical professionalism in Arabian countries: The Four-Gates model. Medical Teacher, 36, S8-S16. https://doi.org/10.3109/0142159X.2014.886013

Document status and date:

Published: 01/04/2014

DOI:

10.3109/0142159X.2014.886013

Document Version:

Publisher's PDF, also known as Version of record

Document license:

Taverne

Please check the document version of this publication:

- A submitted manuscript is the version of the article upon submission and before peer-review. There can be important differences between the submitted version and the official published version of record.

People interested in the research are advised to contact the author for the final version of the publication, or visit the DOI to the publisher's website.

- The final author version and the galley proof are versions of the publication after peer review.

- The final published version features the final layout of the paper including the volume, issue and page numbers.

Link to publication

\footnotetext{
General rights rights.

- You may freely distribute the URL identifying the publication in the public portal. please follow below link for the End User Agreement:

www.umlib.nl/taverne-license

Take down policy

If you believe that this document breaches copyright please contact us at:

repository@maastrichtuniversity.nl

providing details and we will investigate your claim.
}

Copyright and moral rights for the publications made accessible in the public portal are retained by the authors and/or other copyright owners and it is a condition of accessing publications that users recognise and abide by the legal requirements associated with these

- Users may download and print one copy of any publication from the public portal for the purpose of private study or research.

- You may not further distribute the material or use it for any profit-making activity or commercial gain

If the publication is distributed under the terms of Article $25 \mathrm{fa}$ of the Dutch Copyright Act, indicated by the "Taverne" license above, 


\title{
Medical Teacher
}

\section{A Delphi study of medical professionalism in Arabian countries: The Four-Gates model}

\author{
Mohamed M. Al-Eraky, Jeroen Donkers, Gohar Wajid \& Jeroen J. G. van \\ Merrienboer
}

To cite this article: Mohamed M. Al-Eraky, Jeroen Donkers, Gohar Wajid \& Jeroen J. G. van Merrienboer (2014) A Delphi study of medical professionalism in Arabian countries: The Four-Gates model, Medical Teacher, 36:sup1, S8-S16, DOI: 10.3109/0142159X.2014.886013

To link to this article: https://doi.org/10.3109/0142159X.2014.886013

\section{曲 Published online: 11 Mar 2014.}

Submit your article to this journal 줄

山ll Article views: 867

Q View related articles 두

View Crossmark data ¿

Citing articles: 8 View citing articles $\sqsubset \nearrow$ 


\title{
A Delphi study of medical professionalism in Arabian countries: The Four-Gates model
}

\author{
MOHAMED M. AL-ERAKY ${ }^{1,2}$, JEROEN DONKERS ${ }^{3}$, GOHAR WAJID $^{1}$ \& JEROEN J. G. VAN MERRIENBOER ${ }^{3}$ \\ ${ }^{1}$ University of Dammam, Saudi Arabia, ${ }^{2}$ Zagazig University, Egypt, and ${ }^{3}$ University of Maastricht, the Netherlands
}

\begin{abstract}
Background: Medical professionalism has been described as a set of attributes and behaviors, yet the Western frameworks of medical professionalism may not resonate with the cultural values of non-Western countries.

Aim: This study aims to formulate a professionalism framework for healthcare providers as interpreted by local medical professionals in Arabian countries.

Methods: A purposive sample of 17 experts from diverse disciplines participated in a Delphi study in three rounds. Consensus was identified by content analysis and by numerical analysis of responses on the basic attributes of medical professionalism in Arabian context.

Results: Eight professional traits were shortlisted and coupled in four themes (Gates): dealing with self, dealing with tasks, dealing with others and dealing with God. Self-accountability and self-motivation were interpreted from a faithful viewpoint as "taqwa" and "ehtesab", respectively, in Arabic.

Discussion: The Four-Gates Model helps in better understanding of medical professionalism as grounded in the minds and culture of Arabs. The model may act as a genuine framework for teaching and learning of medical professionalism in Arab medical schools.

Conclusion: The study highlights the divergent interpretation of medical professionalism between Western and Arabian contexts. The Four-Gates Model may work for faith-driven societies, but not for non-Muslims Arabs students or teachers or in institutions with humanistic values.
\end{abstract}

\section{Introduction}

Medical professionalism has received growing attention in the literature of medical education, particularly during the past decade. The international accord on the value of professionalism in medicine is not supported with a shared concrete understanding of its nature and elements. There is no conclusive definition for medical professionalism that can be universally addressed in medical education. Professionalism is a generic term (Cruess \& Cruess 2010) and, therefore, should be operationalized into workable attributes and behaviors (Hafferty 2004). Professionalism has been explicitly addressed as an outcome of different medical education systems worldwide, but there is no consensus on the interpretation of the elements contributing to medical professionalism as reported by leading organizations and seminal scholarly reports, as listed in Table 1.

Medical professionalism is a blend of implicit moral commitment and core attributes that are demonstrated in explicit behaviors. To this point, it is significant to highlight the two terms that are used in this discourse, sometimes interchangeably. The term professionalism, which is commonly used in North America, seems to contrast the term professional behavior that is more frequently used in Europe (Papadakis et al. 2004). Professionalism is an abstract term that embraces

\section{Practice points}

- The principles of medical professionalism are culturespecific that should be inferred in light of local tradition, values, beliefs and ethos.

- Eight professional qualities were portrayed in four gates, not in intersecting circles or building boxes to captures the dynamic nature of professionalism, as a pathway.

- The Four-Gate Model is a genuine interpretation of professionalism as grounded in the minds of native Arab medical. The forth gate (Dealing with God) is particularly applicable to societies, where faith represents a cornerstone in communication and the basis for social values.

- When self-accountability is interpreted as "taqwa" in Arabic, it empowers an intrinsic drive for reflection, vigilance and careful estimation of actions and their consequences.

- Self-motivation, if perceived as "ehtesab" in Arabic, is expected to energize excellence and commitment, in the absence of instant rewards by people, official bodies or even the community at large. 
Table 1. Keywords used to indicates elements of medical professionalism, as reported by leading professional organizations and scholarly reports.

\begin{tabular}{|c|c|c|c|c|}
\hline $\mathrm{ABIM}^{\mathrm{a}}$ (1995) & Chard et al. (2006) & Steinert et al. (2007) & Hilton \& Slotnick (2005) & Rogers \& Ballantyne (2010) \\
\hline $\begin{array}{l}\text { - Accountability } \\
\text { - Altruism } \\
\text { - Duty } \\
\text { - Excellence } \\
\text { - Honor } \\
\text { - Integrity } \\
\text { - Respect for others }\end{array}$ & $\begin{array}{l}\text { - Appraisal } \\
\text { - Careers } \\
\text { - Education } \\
\text { - Leadership } \\
\text { - Research } \\
\text { - Teams }\end{array}$ & $\begin{array}{l}\text { - Altruism } \\
\text { - Autonomy } \\
\text { - Commitment } \\
\text { - Competence } \\
\text { - Ethics } \\
\text { - Honesty } \\
\text { - Integrity } \\
\text { - Morality } \\
\text { - Responsibility to society } \\
\text { - Responsibility to the profession } \\
\text { - Self-regulation } \\
\text { - Teamwork }\end{array}$ & $\begin{array}{l}\text { - Ethical practice } \\
\text { - Reflection } \\
\text { - Respect for patients } \\
\text { - Responsibility for actions } \\
\text { - Self-awareness } \\
\text { - Social responsibility } \\
\text { - Teamwork }\end{array}$ & $\begin{array}{l}\text { - Care for colleagues } \\
\text { - Collaboration } \\
\text { - Honesty } \\
\text { - Probity } \\
\text { - Reflection capacity } \\
\text { - Relationship with patients } \\
\text { - Respect for patients } \\
\text { - Responsibility } \\
\text { - Self-awareness } \\
\text { - Teamwork }\end{array}$ \\
\hline
\end{tabular}

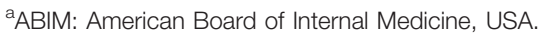

elements like integrity, honor, compassion, altruism, etc. (inner core), while professional behavior refers to the observable manners and conducts of professionals that can be viewed and assessed by the public (outer shell) (Irvine 2005; Leape \& Fromson 2006). It makes sense to approach the core (attributes) of professionalism to learn more about its manifestations on the outer shell (behaviors).

Our quest for understanding medical professionalism is further complicated by the concept of the social contract. Any profession needs two elements to survive; interest of the public in the services provided and trust in the members of that profession. The medical profession is not an exception. Based on knowledge and moral authority of the doctor, a true social contract is built between the professional and the public (Beauchamp 2004). The social contract, as defined by Cruess (2006), is "a contractual relationship with a series of obligations and expectations based on mutual trust between the society and medicine". Different societies vary in their expectations from medicine and, therefore, what is considered professional from an American or European physician may not be perceived so - by patients and society - in Arabian or Asian context.

Professionalism is culture-sensitive and the situations used to measure its constructs or domains should reflect the cultural differences. What are the implications for this notion in medical education? Professionalism can best be taught, learned or assessed when clearly described in its local context. Cruess and Cruess (2006) further advocated that each institution should develop its own so called cognitive base on medical professionalism. This cognitive base encompasses definition, description, elements and attributes of medical professionalism and it dictates what will be taught, evaluated and expected of students, trainees and physicians. We should seek a consensus on the substance of that cognitive base and this must remain consistent throughout the educational process, as a basis for teaching, learning and assessing medical professionalism.

Medical professionalism has been recently addressed as an explicit outcome and as a core value in medical education in Arabian context (Zaini et al. 2011). The Arabian context is a blend of culture, traditions, beliefs and behaviors that are being practiced by nations of Arabian countries in the Middle East where Arabic is the official language and Islam is the religion of the majority of the population. Those behaviors and traditions are not necessarily derived from Islamic doctrines, but some common values have been accepted as the norm among populations of these countries. Although there are differences, "Arab world" is a single, overarching society rather than a collection of several independent states (Barakat 1993). Therefore, it was not surprising to find similarities of the attitudes of Egyptians and Saudis on medical professionalism (Al-Eraky et al. 2013).

Listing the attributes of good physicians was the aim of scholarly studies on medical professionalism in other contexts. Sehiralti et al. (2010) explored professionalism attributes as perceived by first-year students in Turkey, while Brownell and Côté (2001) studied them from the perspectives of senior residents in Canada. Identifying attributes of medical professionals in the Arabian context may follow one of two approaches to content analysis of qualitative data (Hsieh \& Shannon 2005). The first one is called: directive content analysis, where an established framework on professionalism is used as scaffold to structure responses. It is like borrowing someone's hat and check if it may also fit your head. One of these established frameworks was reported by the American Board of Internal Medicine (ABIM), which includes six domains of professionalism; altruism, accountability, excellence, duty, honor and integrity and respect for others (ABIM 1995; see Table 1). Despite it was originally developed in the USA (Blackall et al. 2007; Quaintance et al. 2008; Symons et al. 2009), the ABIM framework of medical professionalism has been found to be also applicable for other contexts in Taiwan (Tsai et al. 2007), Iran (Aramesh et al. 2009), Japan (Suzuki 2009) and also in the Arab world (Al-Eraky \& Chandratilake 2012) with minor adjustments.

Unlike the first approach of the borrowed hat, there is another customized approach, which is based on conventional content analysis (Hsieh \& Shannon 2005). Here, there is no preset reference framework to anticipate elements of professionalism. The absence of a preliminary platform is challenging, but this method has the advantage of gaining direct information on the attributes and behaviors of medical professionalism, as they are grounded in the minds of native experts without imposing preconceived categories or theoretical perspectives, which makes it also more authentic and 
defensible. Knowledge generated from conventional content analysis is founded on participants' unique perspectives who are supposed to respond to open ended questions to explore what they consider as the essential tenets of medical professionalism in the Arabian context.

In brief, the codes of medical professionalism are derived from pre-existent frameworks in the first directive content analysis, while they are defined during data analysis - on the go - in the second approach of conventional content analysis. This study will follow the second approach aiming at bargaining a consensus on the attributes (core) and behaviors (shell) of medical professionalism in the Arabian context. This approach is expected to obtain a better understanding of the nature of medical professionalism as perceived by Arabs. We aim to develop a framework on medical professionalism that is genuine to Arabian countries.

\section{Method}

\section{Study design}

For conventional content analysis, we used a Delphi technique in a series of sequential questionnaires or "rounds", interspersed by controlled feedback. The Delphi technique is an established method of harnessing the opinions of an often diverse group of experts on practice-related problems (Powell 2003). We pursue consensus on essential professional values and behaviors among selected health professionals and educators. The Delphi process extended to three rounds in an iterative manner; i.e. stimulus of the second round is decided based on anonymous responses of the first round and so on.

\section{Participants}

The Delphi does not call for expert panels to be representative samples for statistical purposes, but representativeness is assessed on the qualities of the expert panel rather than its numbers (Powell 2003). The selection of participants for a Delphi study should not necessarily be random, but may be purposive to epitomize relevant groups (Polit \& Beck 2006). Our sampling technique was designed to maximize diversity of participants from both genders. Invited experts had to represent a wide spectrum of specialties and background from four Arab universities from Egypt, Saudi Arabia, Oman and Sudan. Almost one quarter of Arabian populations lives in the first two countries and, therefore, we purposely enrolled more experts from Egypt and Saudi Arabia. Participants fulfilled particular inclusion criteria, as they had to be (a) native Arabic speakers; (b) medical or dental professionals in clinical and non-clinical disciplines, and (c) engaged in undergraduate medical education and/or residency training. Four dentists were included along with 13 medical doctors, because both professions are entitled as doctors in our culture. The demography of the members of the reference panel is shown in Table 2. Almost half of the candidates were certified medical educators and, therefore, were quite oriented about the value of the concept of professionalism in medical education.

An invitation was sent via e-mail as blind carbon copy (bcc) to all potential members of the reference panel with
Table 2. Demography of experts in the reference panel, which represents the diversity of gender and background of its members.

\begin{tabular}{|c|c|c|c|c|}
\hline Panelist No. & Gender & Profession & Setting ${ }^{a}$ & Specialty \\
\hline 1 & M & Medicine & Clinical & Psychiatry \\
\hline 2 & $\mathrm{~F}$ & Medicine & Clinical & Surgery \\
\hline 3 & M & Medicine & Academic & Medical Education \\
\hline 4 & M & Dentistry & Clinical & Dental Radiology \\
\hline 5 & $\mathrm{~F}$ & Medicine & Academic & Microbiology \\
\hline 6 & M & Dentistry & Clinical & Maxillofacial surgery \\
\hline 7 & M & Medicine & Clinical & Pediatrics \\
\hline 8 & $\mathrm{M}$ & Medicine & Clinical & Pediatrics \\
\hline 9 & M & Medicine & Clinical & Pediatrics \\
\hline 10 & F & Medicine & Academic & Physiology \\
\hline 11 & $\mathrm{~F}$ & Medicine & Clinical & Hepatology \\
\hline 12 & $\mathrm{~F}$ & Dentistry & Academic & Dental Pathology \\
\hline 13 & $\mathrm{~F}$ & Medicine & Academic & Medical Education \\
\hline 14 & M & Medicine & Clinical & Family Med. \\
\hline 15 & $F$ & Medicine & Academic & Biochemistry \\
\hline 16 & M & Medicine & Clinical & Emergency \\
\hline 17 & M & Dentistry & Clinical & Pediatric Dentistry \\
\hline
\end{tabular}

${ }^{a}$ Clinical setting involves direct patient care while academic does not.

explanation of the study objectives and their expected role. There was no direct communication between experts on the study subject and none of them was aware about the list of participants. Three rounds were planned and administered. In each round participants reflected on stimuli designed by authors then confirm their inputs to reach agreement.

\section{Round 1}

The first round questionnaire is recommended to be unstructured and include open-ended questions to motivate participants to elaborate on the topic under investigation and increase the richness of the data collected (Rowe 1994; Powell 2003). We started by asking experts to answer four questions regarding: what a professional doctor should be, should do, should not be and should not do. This round intended to gather all possible attributes and behaviors of medical professionalism as well as unprofessional ones. A qualitative content analysis of responses was then undertaken and this provides the basis for subsequent rounds.

\section{Round 2}

Respondents to round 1 were contacted and provided with the results and they were asked to select the top-10 foremost qualities for medical professionalism. The sum of votes was calculated and professional attributes of the highest votes were sorted in higher-order categories.

\section{Round 3}

All respondents from round 2 received one more request to review and confirm their selection as categorized in four main themes. A new framework was designed to describe the domains and traits of medical professionalism in Arabian context.

\section{Data analysis}

Qualitative content analysis focused on manifest content only (Kondracki et al. 2002), because all communication was 
written to and from panelists via emails. Knowledge generated from our content analysis is based on participants' unique perspectives as grounded in the actual data. We followed the conventional approach to content analysis to gain direct information from study participants without imposing preconceived categories or theoretical perspectives. The response from each panelist was considered the unit of analysis (answers to the four questions in Round 1), which included a number of meaning units (texts). Meaning units represented features of un/professionalism and varied in length, ranging from one word, e.g. "respect" and "truthful" to a couple of lines, e.g. "doctors should keep secrets of their patients and never disclose them to people outside the healthcare practice". Short meaning units were condensed and coded as such, but longer ones were shortened with the preservation of their gist to form condensed meaning units. Many condensed meaning units were found similar and shared the same synonyms or antonyms, e.g. "truthful", "telling the truth" and "lying", and therefore one code was given to them all, e.g. truthful, as shown in the last column of Table 3. Codes were then grouped under higher headings (categories), which were eventually clustered in four themes.

Credibility can be established through activities such as peer debriefing and review of content analysis (Manning 1997). Two authors contributed to the content analysis independently and then agreed on the final codes, categories and themes. Consensus was identified by content analysis (in round 1 and 3 ) and by numerical analysis (in round 2).

\section{Results}

\section{Round 1}

Of the 21 invited experts, 17 responded to round 1 and sent their answers to the given four open-ended questions (Figure 1). Each participant listed 2-5 attributes (meaning units) to catalog professional and unprofessional manners of doctors. Meaning units reached up to 192 in total and they were condensed, coded, merged and sorted into 24 higher order categories to portray qualities of medical professionalism in Arabian context (see Appendix 1). The categories were decided by two authors and send back to panelists for evaluation.

\section{Round 2}

Panelists listed the top-10 professional categories (of the 24), which they perceive as essential without ranking from 1 to 10 . Eight categories received nine votes (half of participants plus one) or more, and therefore considered of prime importance. Authors found links between each pair of categories and, therefore, provide the rationale for the Four-Gates Model of Arabian medical professionalism, as shown in Figure 2.

Grouping professional qualities in clusters was recently reported in a number of scholarly articles on medical professionalism (Chandratilake et al. 2010; van Luijk et al. 2010). The Four-Gates Model encompasses eight professional traits as coupled in four themes; dealing with self, dealing with task, dealing with others and dealing with God. The first gate"dealing with self" - included two attributes: self-awareness and self-management. Doctors should learn about themselves first (dealing with self) to recognize their potentials and limitations, then find out how to fulfill their needs and learning gaps (Self-awareness). Self-management is not only about time management, but about life management. Medical professionals have to allocate the appropriate time and effort for their various professional roles as clinicians, teachers, scholars and community leaders. At the same time, they should also attend to their personal and family responsibilities.

The second gate - "dealing with tasks" - is mainly about excellence and reflection. Medical professionals have to commit to professional development to fulfill the growing patients' needs and keep abreast with advancement of technology in diagnosis and treatment. Aspiring towards excellence is not only for clinical practice, but also to enhance performance in teaching and research as well. Reflective practice is a key attribute while dealing with any task, because such skill helps doctors to identify their learning gaps and so it is also connected with dealing with self in the first gate.

The third gate - "dealing with others" - is about communication with patients, colleagues, supervisors, subordinates and may extent to other members of the institution and the

Table 3. Examples of meaning units, condensed meaning units and codes.

Meaning unit

The doctor should be transparent with patients and never lie to them about their illness, diagnosis and management

Doctors should not lie

Always tell the truth

Respect patients in diagnosis and management

Respect

Respect students in front of patients, nurses, peers

Do not underestimate views of other doctors

Professional doctors should keep the secrets of their patients and never disclose them to outsiders

Doctors should know his limits and shortcomings

Doctors should learn about their potentials and strengths

Doctors should create a balance between personal life and professional commitments

Doctors should not be committed to extra duties that interfere with their normal life
Condensed meaning unit

Code

Transparent and truthful with patients

Truthful

Do not lie

Tell the truth

Respect patients

Respect

Respect students

Respect colleagues

Keep patient secrets

Know about own limits

Learn about own potentials

Balance between personal and professional duties

No extra duties that interfere with normal life
Truthful

Truthful

Respect

Respect

Respect

Respect

Confidentiality

Self-awareness

Self-awareness

Balanced life

Balanced life 


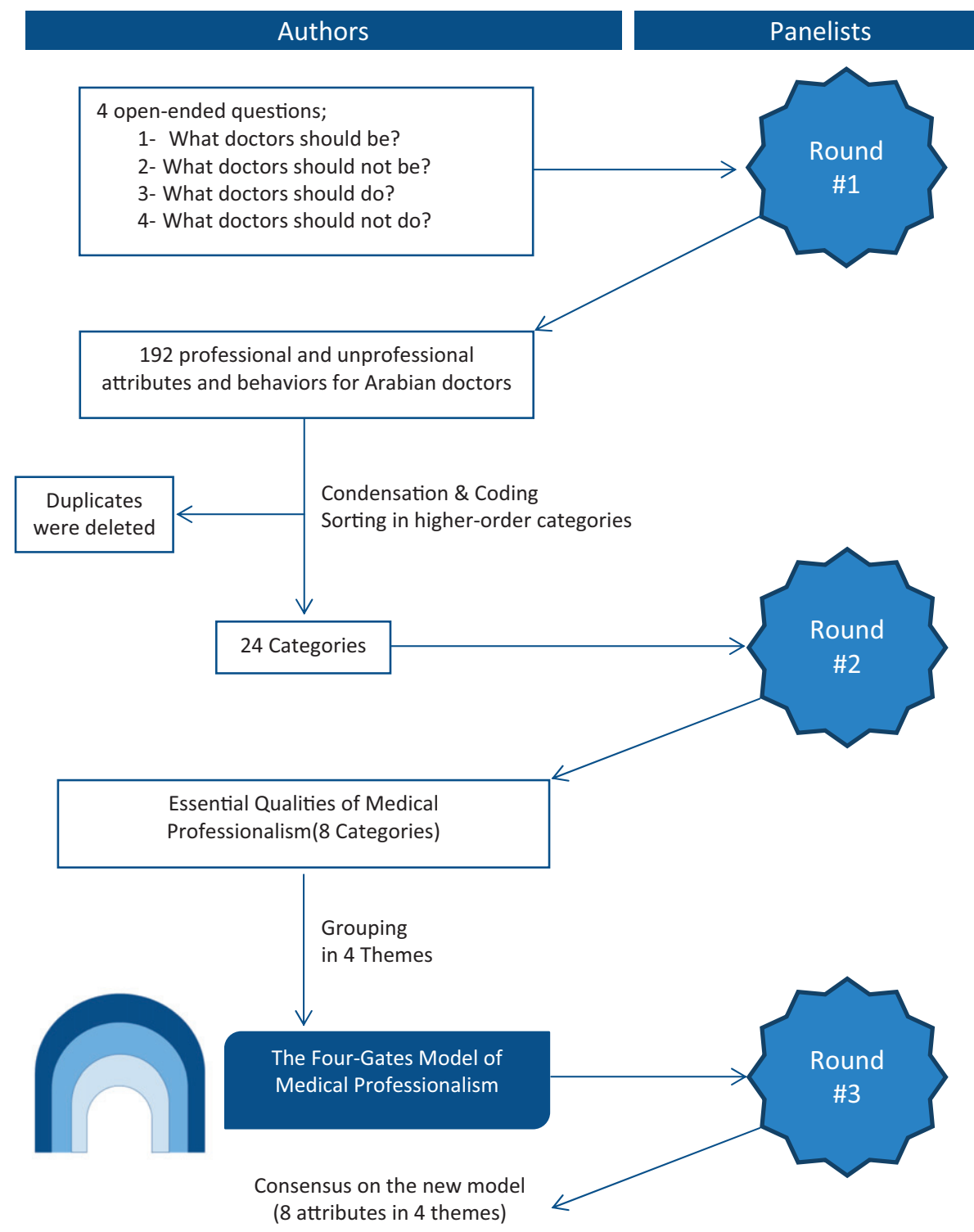

Figure 1. Storyboard of the Delphi technique showing the flow of communication between authors (on the left) and panelists (on the right) throughout the process over three rounds.

community at large. Experts of the panel found that respect and confidentiality are key attributes when dealing with others.

The fourth gate - "dealing with God" - is fairly new to the main stream literature on medical professionalism. Selfaccountability and self-motivation have been addressed in the literature, but the current study interprets them from a different take, as linked to a Super Power (God) that monitors and rewards for all actions, as it will be further elaborated in the Discussion section.

\section{Round 3}

Participants agreed that the Four-Gate model is relevant to Arabian context and represents the most essential elements of medical professionalism that should be taught, learned and assessed in medical education.

\section{Discussion}

This study is an attempt to identify attributes of Arabian professional doctors as grounded in the minds of native Arabian members of the medical and dental academic and clinical community. In a Delphi process, we have reached an agreement to list eight principal traits of medical professionalism in Arabian context, which can be compared against the keywords reported from Western perspectives in Table 1 . Shared qualities included selfawareness, accountability, excellence, reflective practice and respect. No list, though, is ever claimed to be comprehensive or conclusive. The third gate addressed dealing with others, but did not attend to attributes like collaboration, teamwork, leadership and social accountability. Yet, the Four-Gate Model stands out with a new theme, in its fourth gate (dealing with God), which was rarely addressed in the discourse of medical professionalism in the Western context. 


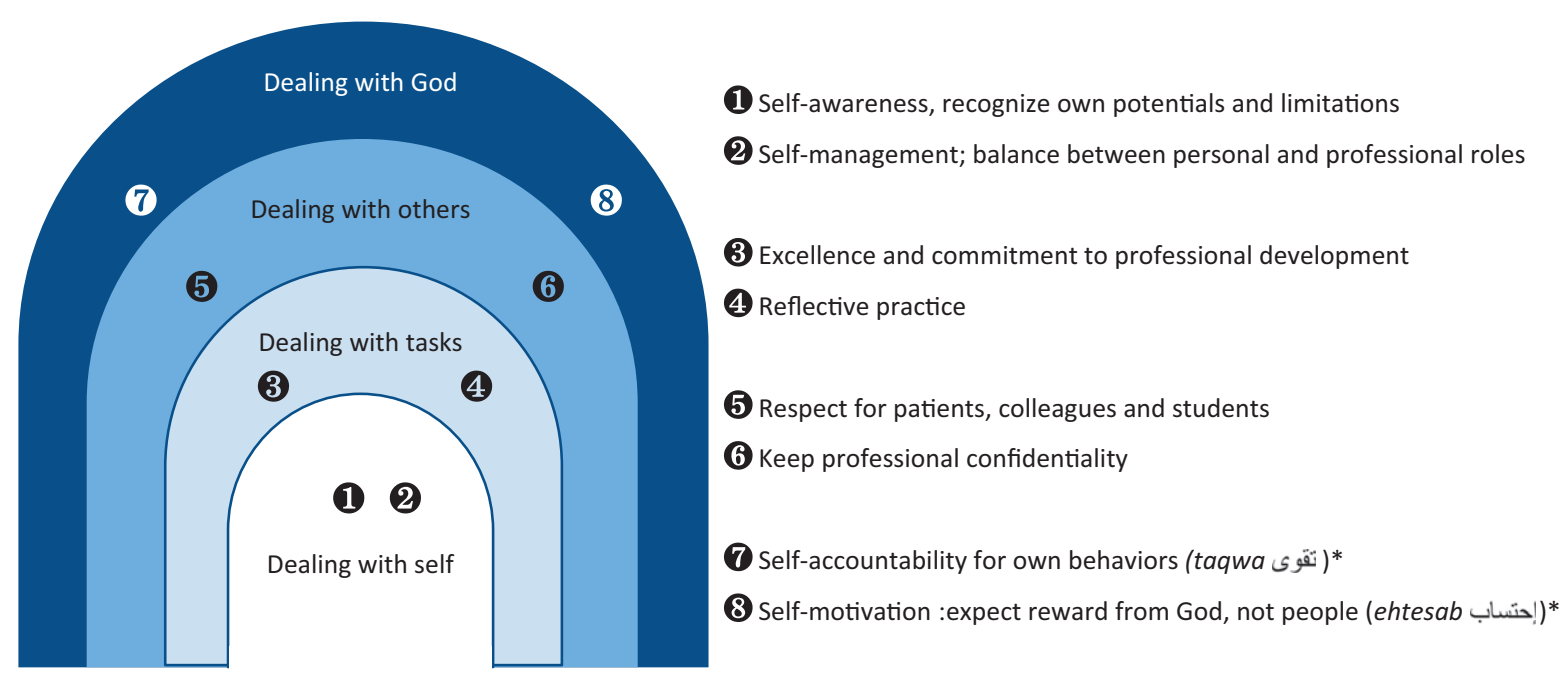

Figure 2. The Four-Gates Model of Arabian Medical Professionalism. *Arabic synonyms (in Italic) and Arabic script to indicate faith-rooted concept. According to Barakat (1993), faith is what more than $90 \%$ of Arabs share, regardless of their diverse affiliations and nationalities.

\section{Faith and medical professionalism}

Faith, in God (Allah) and the hereafter (Day of Judgment), is what more than $90 \%$ of Arabs share, regardless of their diverse affiliations and nationalities (Barakat 1993). Like the metaphor of the elephant in the room, Arabs (particularly Muslims) tend to overlook faith as a core cultural value of medical students, teachers and patients. In Arab countries, linking selfaccountability and self-motivation to faith (dealing with God) might possibly lead to tangible improvement in professional conducts. Such improvement, in presence of good role models who practice what they preach, may be expected to be sustained, even in absence of direct supervision or instant reward. Faith may further provide the doctor with an internal North and insight to navigate his/her path in a sophisticated healthcare environment. This study attested that faith plays an axiomatic role in shaping medical professionalism in Arabian context, which is clearly demonstrated in the two attributes in the fourth gate; self-accountability and self-motivation.

Self-accountability for own behaviors in absence of human monitoring is also known as "taqwa تقوى" in Arabic. Doctors are smart creatures who can cunningly commit themselves to the minimum without being legally caught. It is time to shift from extrinsic drives which we trust to moderate medical practice. The medical profession is not (only) governed by professional bodies, rules, patients' needs or societal expectations. There is something far beyond the social contract with its series of expectations and obligations between society and medical profession. When self-accountability is interpreted as "taqwa", it empowers an intrinsic drive for reflection, vigilance and careful estimation of actions and their consequences, because they are witnessed by God, even in absence of people.

Self-motivation - or "ehtesab إحتساب" - in Arabian context is not fueled by rewards from people (patients, families, individuals, professional bodies or community at large), but it is when doctors do their best in clinical work, teaching and research duties and then expect reward from God or a superpower that owns everything, whether in this life or afterwards. This makes it less necessary to rely on immediate carrots (incentives, decoration and acknowledgment) to motivate doctors to stick to professional conduct. The notion of the genuine self-motivation - in a faithful society - is expected to energize excellence and commitment. Think of an Arab doctor who is working for long duty hours in night shifts and is doing utmost efforts to provide the finest medical care to never satisfied patients, family or employers. Faith in God almighty who compensates people for their deeds, may inspire that doctor to replenish his/her passion for services and commitment to excellence. Self-motivation in an Arabian or religious cultures, therefore, can probably be better linked to the divine accountability than social accountability.

\section{Salient features of the Four-Gate Model}

The Four-Gates Model has also four salient features. First, the Four-Gates model suggests a move from the classical perception of medical professionalism as a short list of standalone attributes (as in Table 1), to link them in a structural pattern of connected professional qualities as coupled in four logical domains (Gates). This may serve as a helpful mnemonic to facilitate educational interventions, like the classical 10 questions to be asked when planning a course or a curriculum (Harden 1986), which were coupled in five twin concepts (AlEraky 2012, Figure 3). It is important for medical students and teachers to correlate professional attributes, as demonstrated in the Four-Gates Model, because such coupling is expected to advance teaching and learning of medical professionalism. For instance, Self-awareness and self-management (\#1 and \#2 in the smaller arch) are interconnected, because they both contribute to emotional intelligence, which maps on to professionalism (Lewis et al. 2005) and is gaining more attention in medical education (Cherry et al. 2012).

Second, four of the eight attributes started with "self". This observation implies the value of developing and nurturing selfawareness and self-management (\#1 and \#2 in the inner arch) 
as the route to the inner peace and having self-accountability and self-motivation ( $\# 7$ and $\# 8$ in the outer arch). Medical professionalism starts by preparing professionals - themselves - to work in a complex healthcare system, with major key players like pharmaceutical and insurance companies along with the escalating stress from vocal patients' complaints and longer duty hours from one hand, and commitment to other non-clinical roles like teaching and research, let alone the family responsibilities of doctors on the other hand. Countless temptations, precaution and obligations made modern medical profession incredibly sophisticated, like no other professions, simply because doctors are dealing with human lives. In concert with being competent, fulfilling patients' needs and meeting societal expectations, doctors also need to learn about how to keep their internal serenity and true North. Success and failure by the way - starts from within, but unfortunately, these notions are rarely attended to in the discourse of medical professionalism. Addressing professional qualities about self may stimulate further discussion in this track.

Third, the model stimulates lateral thinking on medical professionalism. Notice that the eight qualities were portrayed in gates, not in intersecting circles or building boxes. Illustrating domains of medical professionalism in gates captures the dynamic nature of professionalism, as a pathway; a notion that resonates well with the term "aspiring towards" that was eloquently used by the American Board of Internal Medicine when listing attributes of medical professionalism in their milestone publication named: "Project Professionalism". The model implies that: being a professional doctor is not a destination, but rather a lifelong journey through these four gates. The gates were intentionally sketched of variable heights. The forth gate is not only larger, but it also overarch other gates, because it acts as a beacon in the dark ocean with high tides.

Fourth, despite the Four-Gates Model has emerged from Arabian background, it may be also applicable (after validation) to other similar cultures, where faith represents a cornerstone in communication and the basis for social values. Faith, however, was not reported as a key principle in interpreting professionalism in non-Arab countries with Muslim majorities like Iran (Aramesh et al. 2009) or Turkey (Sehiralti et al. 2010). The fourth gate of the model should be addressed with care with non-believers in Arab countries or in institutions whose mission and vision are based on humanistic rather than religious principles. Each institution should decide on the cognitive base of professionalism that will remain constant throughout the continuum of medical education (Cruess \& Cruess 2006).

Professionalism is a social construct and is culture-sensitive. Regional similarities and differences in understandings of professionalism have been reported by medical practitioners in UK, Europe, North America and Asia (Chandratilake et al. 2012). In China, professionalism encompasses Confucian values like ren ai (humane love) and gong xin (public spiritedness) (Pan et al. 2013). Professionalism, therefore, should be interpreted in view of local traditions and ethos (AlEraky \& Chandratilake 2012). To the best of our knowledge, this study provides a basis for understanding professionalism apart from Western ideologies, but as grounded in the minds of local medical practitioners in the Arab region.

\section{Limitations}

This study has several limitations. The study relied on a convenience sample of Arab professionals, so results may not be applicable to the general population. Other stakeholders like medical students, patients, policy makers and community leaders may be included in future studies to tap on their views on the Four-Gates Model. The fourth gate included two attributes of taqwa and ebtesab, which are known to the Muslim majority of Arabs, but it may limit the applicability of the model on Arab non-Muslim minorities. To avoid this, educators may focus on the generic understanding of selfaccountability and self-motivation and demonstrate relevant examples in the daily life of Arabs of all nationalities and beliefs of these two professional qualities. Some attributes of the Four-Gates Model might be challenging for teaching, learning and assessment, particularly those in the inner and outer gates of the model. These attributes may need more attention in future studies to explore them further and decide the best practice to address them in undergraduate and postgraduate curricula.

\section{Conclusion}

The new Four-Gates Model on medical professionalism is expected to improve the interpretation of medical professionalism in Arabian context, beyond fulfilling patients' needs and meeting societal expectations. This study suggested that faithdriven concepts like taqwa and ehtesab can be used to advance professionalism education and practice of Arab medical practitioners. These notions, however, may not be all relevant to non-Muslims Arabs or in institutions whose principles are based on humanistic values. This study stimulates further discussion on interpretation of medical professionalism in view of local traditions and ethos.

\section{Notes on the contributors}

MOHAMED M. AL-ERAKY, MBBCh, MSc, MMedEd, is a lecturer of medical education at the University of Dammam, Saudi Arabia. He was also a founding member of Medical Education Development Center at Zagazig University, Egypt. Dr. Al-Eraky is currently a PhD fellow at the University of Maastricht, the Netherlands.

JEROEN DONKERS, PhD, is an assistant professor, at the Department of Educational Development and Research, Faculty of Health, Medicine, and Life Sciences, Maastricht University, the Netherlands.

GOHAR WAJID, PhD, is an Assistant Professor of Medical Education, University of Dammam, Saudi Arabia. He is consultant to the Master in Health Professions Education Programs at Khyber Medical University and the University of Lahore, Pakistan.

JEROEN J. G. VAN MERRIENBOER, PhD, is a Full Professor of Learning and Instruction at the Department of Educational Development and Research, Faculty of Health, Medicine and Life Sciences, Maastricht University. He is a Research Programme Director of the School of Health Professions Education and Scientific Director of the Interuniversity Center for Educational Research. 


\section{Acknowledgements}

Authors would like to thank members of the reference panel who contributed to the success of this study. Their dedication and expertise were invaluable to constructing the Four-Gates Model of medical professionalism in Arabian context. Experts contributed to the Delphi study from Egypt, Oman, Saudi Arabia and Sudan. The names of the professors and doctors are alphabetically arranged as follows: Abdel-Aziz El-Feky. Amira Waly, Basem El-Deek, Hassan Abol-Khair, Heba Mohtadi, Hesham Marei, Khalid Al-Umran, Khalid Kamaleddin, Mohamed Al-Qahtani, Mona Al-Sheikh, Mona Ismail, Neveen Mokhtar, Omayma Aly, Shaher Al-Shehry, Shereen El-Tarhouny, Yousef Al-Wehsahi and Yousef AlYousef.

The publication of this supplement has been made possible with the generous financial support of the Dr Hamza Alkholi Chair for Developing Medical Education in KSA.

Declaration of interest: The authors report no declaration of interest to report in relation to this article.

\section{References}

ABIM: American Board of Internal Medicine. 1995. Project professionalism. Philadelphia: American Board of Internal Medicine. pp 5-6. [Accessed 29 September 2013]. Available from: http://www.abimfoundation.org/ Resource-Center/Bibliography/ /media/Files/Resource\%20Center/ Project $\% 20$ professionalism.ashx.

Al-Eraky MM. 2012. Curriculum navigator: Aspiring towards a comprehensive package for curriculum planning. Med Teach 34(9):724-732.

Al-Eraky MM, Chandratilake M. 2012. How medical professionalism is conceptualised in Arabian context: A validation study. Med Teach 34(Suppl 1):S90-S95.

Al-Eraky MM, Chandratilake M, Wajid G, et al. 2013. Medical professionalism: Development and validation of the Arabian LAMPS. Med Teach 35(Suppl 1):S56-S62.

Aramesh K, Mohebbi M, Jessri M, Sanagou M. 2009. Measuring professionalism in residency training programs in Iran. Med Teach 31(8):e356-e361.

Barakat H. 1993. The Arab world: Society, culture and state. Berkeley: University of California Press.

Beauchamp G. 2004. The challenge of teaching professionalism. Ann Acad Med Singapore 33(6):697-705.

Blackall GF, Melnick SA, Shoop GH, et al. 2007. Professionalism in medical education: The development and validation of a survey instrument to assess attitudes toward professionalism. Med Teach 29(2-3):e58-e62.

Brownell AK, Côté L. 2001. Senior residents' views on the meaning of professionalism and how they learn about it. Acad Med 76:734-737.

Chandratilake M, McAleer S, Gibson J, Roff S. 2010. Medical professionalism: what does the public think? Clin Med 10(4):364-9.

Chandratilake M, McAleer S, Gibson J. 2012. Cultural similarities and differences in medical professionalism: A multi-region study. Med Educ 46(3):257-266.

Chard D, Elsharkawy A, Newbery N. 2006. Medical professionalism: the trainees' views. Clin Med 6(1):68-71.

Cherry MG, Fletcher I, O'Sullivan H, Shaw N. 2012. What impact do structured educational sessions to increase emotional intelligence have on medical students? BEME Guide No. 17. Med Teach 34(1):11-19.

Cruess RL, Cruess SR. 2006. Teaching professionalism: General principles. Med Teach 28(3):205-208.
Cruess RL, Cruess SR. 2010. Professionalism is a generic term: practicing what we preach. Med Teach 32(9):713-714.

Cruess SR. 2006. Professionalism and medicine's social contract with society. Clin Orthop Relat Res 449:170-176. Review.

Hafferty F. 2004. Toward the operationalization of professionalism: A commentary. Am J Bioeth 4(2):28-31.

Harden RM. 1986. Ten questions to ask when planning a course or curriculum. Med Educ 20(4):356-365.

Hilton SR, Slotnick HB. 2005. Proto-professionalism: how professionalisation occurs across the continuum of medical education. Med Educ 39(1):58-65.

Hsieh HF, Shannon SE. 2005. Three approaches to qualitative content analysis. Qual Health Res 15(9):1277-1288.

Irvine D. 2005. Patients, professionalism, and revalidation. $\mathrm{Br}$ Med J 330(7502):1265-1268.

Kondracki NL, Wellman NS, Amundson DR. 2002. Content analysis: Review of methods and their applications in nutrition education. J Nutr Educ Behav 34(4):224-230. Review.

Leape LL, Fromson JA. 2006. Problem doctors: Is there a system-level solution? Ann Intern Med 144(2):107-115.

Lewis N, Rees C, Hudson JN, Bleakley A. 2005. Emotional intelligence in medical education: Measuring the unmeasurable? Adv Health Sci Educ Theory Pract 10:339-355.

Manning K. 1997. Authenticity in constructivist inquiry: Methodological considerations without prescription. Qualit Inq 3:93-115.

Pan H, Norris JL, Liang YS, et al. 2013. Building a professionalism framework for healthcare providers in China: A nominal group technique study. Med Teach 35(10):e1531-e1536.

Papadakis MA, Hodgson CS, Teherani A, Kohatsu ND. 2004. Unprofessional behavior in medical school is associated with subsequent disciplinary action by a state medical board. Acad Med 79(3):244-249.

Polit DF, Beck CT. 2006. The content validity index: Are you sure you know what's being reported? Critique and recommendations. Res Nurs Health 29(5):489-497.

Powell C. 2003. The Delphi technique: Myths and realities. J Adv Nurs 41(4):376-382. Review.

Quaintance JL, Arnold L, Thompson GS. 2008. Development of an instrument to measure the climate of professionalism in a clinical teaching environment. Acad Med 83(10 Suppl):S5-S8.

Rogers W, Ballantyne A. 2010. Towards a practical definition of professional behaviour. J Med Ethics 36(4):250-4.

Rowe E. 1994. Enhancing Judgement and Decision Making: A critical and empirical investigation of the Delphi technique. Unpublished $\mathrm{PhD}$ Thesis, University of Western England, Bristol.

Sehiralti M, Akpinar A, Ersoy N. 2010. Attributes of a good physician: What are the opinions of first-year medical students? J Med Ethics 36(2):121-125.

Steinert Y, Cruess RL, Cruess SR, Boudreau JD, Fuks A. 2007. Faculty development as an instrument of change: A case study on teaching professionalism. Acad Med 82(11):1057-1064.

Suzuki N. 2009. [Certification for specialists on neurology by Japanese Society of Neurology]. Rinsho Shinkeigaku 49(11):745-746.

Symons AB, Swanson A, McGuigan D, et al. 2009. A tool for self-assessment of communication skills and professionalism in residents. BMC Med Educ 9:1.

Tsai TC, Lin CH, Harasym PH, Violato C. 2007. Students' perception on medical professionalism: The psychometric perspective. Med Teach 29(2-3):128-134.

van Luijk SJ, Gorter RC, van Mook WN. 2010. Promoting professional behaviour in undergraduate medical, dental and veterinary curricula in the Netherlands: Evaluation of a joint effort. Med Teach 32(9):733-739.

Zaini RG, Bin Abdulrahman KA, Al-Khotani AA, et al. 2011. Saudi Meds: A competence specification for Saudi medical graduates. Med Teach 33(7):582-584. 


\section{Appendix}

Appendix 1. Attributes and behaviors of Arabian medical professionals, as retrieved from content analysis of narratives from medical professionals and educators.

Attributes of medical professionalism in Arabian context

1. Altruism; put patient interest first

2. Competent, skillful and knowledgeable

3. Excellence and commitment to professional development.

4. Fair with everyone

5. Flexible, ready to seek help and benefit from feedback

6. Honest, always

7. Humble with everyone

8. Keep professional confidentiality

9. Leadership

10. Listen, smile and communicate well with patients and colleagues

11. Recognize different professional roles; as a clinician, teacher, mentor and scholar

12. Reflect on practice

13. Respect for patients, colleagues and students

14. Scholarship and evidence-based practice

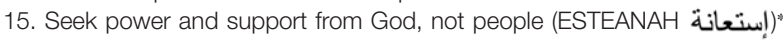

16. Self-accountability for own behaviors and stay away from suspicions (TAKWA تقوى)*

17. Self-awareness; recognize own potentials and limitations

18. Self-Management; balance between personal and professional roles

19. Self-monitoring of behaviors in the absence of supervision (MORAKABAH مر اقبة):

20. Self-motivation and expect reward from God, not people (EHTESAB إحتسابة)

21. Show mercy, care, empathy and sympathy with patients and juniors.

22. Teamwork

23. Truthful, always

24. Volunteer support when needed

*Arabic expressions that eloquently describes each concept in one word.

Attributes in boldface were shortlisted by experts to contribute to the Four-Gates Model. 